\title{
POTENSI EKSTRAK RUMPUT LAUT (Eucheuma cottoni) SEBAGAI ANTIOKSIDAN
}

\author{
Aminah $^{1}$, Hamsinah ${ }^{1}$, Nurmila A. Abiwa', Sulasmi Anggo² \\ ${ }^{1}$ Fakultas Farmasi, Universitas Muslim Indonesia, Makassar \\ ²Universitas Muhammadiyah Luwuk Banggai \\ Email: aminah.aminah@umi.ac.id
}

\begin{abstract}
Seaweed (Eucheuma cottoni) is a marine biota that is often used as an additive to pharmaceutical products that function as thickener. But seaweed, which is rich in carrageenan, also contains vitamin $C$ which has the potential as an antioxidant. The method used was to test the antioxidant activity of seaweed extract (Eucheuma cottoni) with the DPPH (1,1-Diphenyl-2-Picrylhdrazil) damping method. The test sample was in the form of seaweed ethyl acetate extract, where the standard standard of comparison of quarsetin and seaweed extract samples was made in 5 variations of concentration. The standard curve produced by quarsetin with concentrations of 2, 4, 6, 8, $10 \mathrm{ppm}$ at the maximum wavelength DPPH $514,942 \mathrm{~nm}$. The results obtained by the Kuarsetin standard with regression values $y=6.4765 x+7.567$, the correlation value $r=0.99959$ and $I C_{50}=6.48$ (very strong antioxidant activity) while the ethyl acetate extract of seaweed with concentrations of $600,800,1000$, $1200,1400 \mathrm{ppm} \%$ inhibition was obtained with regression values $y=0.0104 x+16.708$, the correlation value $r=0.9972$ and $I C_{50}=3201.15$ (very weak antioxidants). So it can be concluded that the seaweed ethyl acetate extract has the potential for antioxidant activity.
\end{abstract}

Key words: Seaweed (Eucheuma cottoni), antioxidants,DPPH

\section{PENDAHULUAN}

Rumput laut merupakan salah satu sumber devisa negara dan sumber pendapatan bagi masyarakat pesisir. Selain dapat digunakan sebagai bahan makanan, minuman dan obat-obatan, beberapa hasil olahan rumput laut seperti agar-agar, alginat dan karaginan merupakan senyawa yang cukup penting dalam industry. ${ }^{1}$

Eucheuma cottonii Doty. adalah contoh tumbuhan laut yang kandungan utamanya adalah kappa-karagenan yang berpotensi sebagai pelindung surya dan nutrisi. Karagenan dalam Eucheuma cottonii Doty. berpotensi sebagai proteksi UV B dan

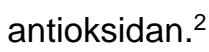

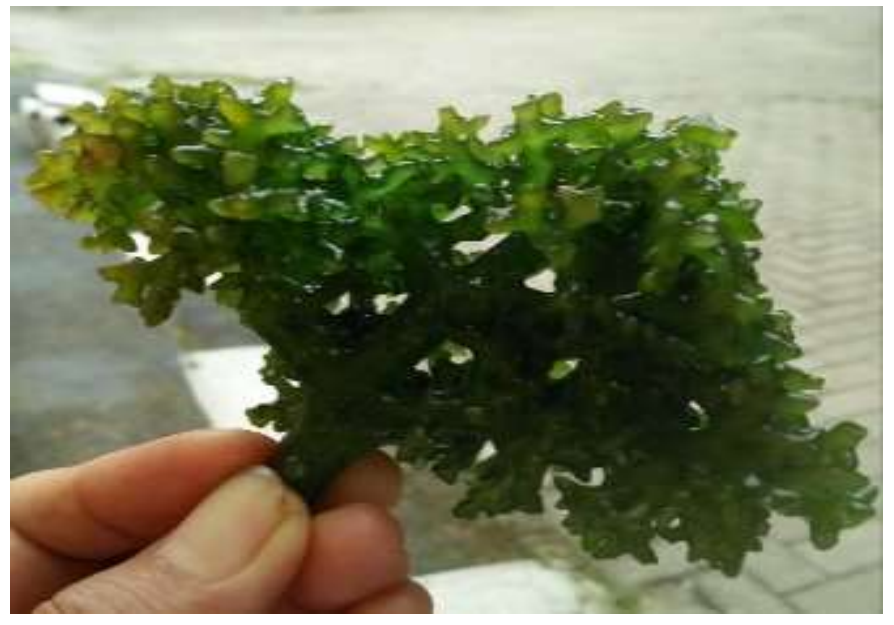

Gambar 1. Rumput Laut (Eucheuma cottonii) 
Antioksidan adalah senyawa yang bertugas untuk menetralisir peningkatan radikal bebas, melindungi sel dari efek toksik yang dihasilkan serta berkontribusi dalam pencegahan penyakit-penyakit. Selama ini antioksidan sintetik sering digunakan karena dapat menetralkan radikal bebas namun dapat menimbulkan efek toksik. Hal tersebut membuat para peneliti semakin berminat meneliti antioksidan alami terutama yang berasal dari tanaman karena lebih aman daripada antioksidan sintetik dan mempunyai manfaat luas dibidang pengawetan pangan, kesehatan, kosmetik dan pencegahan penyakit yang disebabkan oleh radikal bebas. ${ }^{2}$

\section{METODE PENELITIAN}

Alat dan Bahan

Alat-alat yang digunakan adalah ayakan, mikropipet (Memmert), spektrofotometer UV-Vis (Apel® PD 302UV), timbangan analitik (Caratseries), seperangkat alar gelas dan spektrofotometri Uv-Vis, vortex, dan water bath. Bahan-bahan yang digunakan pada penelitian ini antara lain aquadest, DPPH (1,1-diphenyl-2-picrylhydrazyl), ekstrak etil asetat Rumput laut (Eucheuma cotonii), Kuarsetin p.a, Etil asetat p.a, kertas label dan Aluminium foil.

\section{Prosedur penelitian}

\section{Penyediaan sampel $^{9}$}

Rumput laut jenis Eucheuma cotonii sebanya 100 gram dicuci dengan air untuk menghilangkan kotoran yang menempel, kemudian dikeringkan ditempat yang teduh sampai diperoleh berat konstan. Sampel yang telah kering dipotong-potong kecil kemudian dihaluskan dengan blender, lalu di saring.

\section{Ekstraksi Rumput laut (Eucheuma cotonii)}

Rumput laut diekstraksi dengan cara mencampur 5 gram serbuk rumput laut, dan ditambahkan masing-masing larutan penyari etil asetat hingga filtrate menjadi bening.

\section{Pengujian antioksidan menggunakan metode peredaman DPPH. ${ }^{10}$}

\section{Pembuatan larutan}

Larutan DPPH 50 ppm dibuat dengan cara ditimbang sebanyak $5 \mathrm{mg}$ serbuk DPPH kemudian dilarutkan dengan $100 \mathrm{~mL}$ etanol dalam labu ukur.

\section{Penentuan panjang gelombang maksimum}

Penentuan panjang gelombang maksimum DPPH dilakukan dengan cara memipet $1 \mathrm{~mL}$ larutan DPPH 50 ppm direaksikan dengan $2 \mathrm{~mL}$ etanol, kemudian diukur pada panjang gelombang maksimum pada range 400-600 $\mathrm{nm}$ dan diperoleh panjang gelombang maksimum $515 \mathrm{~nm}$.

\section{Pengukuran aktivitas antioksidan sampel pembanding Kuarsetin.}

Dibuat larutan stok 30 ppm dengan cara menimbang kuarsetin setara $3 \mathrm{mg}$ dan dilarutkan dengan etanol sambil diaduk dan dihomogenkan lalu cukupkan volumenya hingga $100 \mathrm{~mL}$, kemudian dilakukan pengenceran. Larutan stok dipipet 330, 660, 1000, 1330 dan $1660 \mu \mathrm{L}$, dicukupkan dengan etanol sampai volume akhir $5 \mathrm{~mL}$ (2 ppm), (4 ppm), (6 ppm), (8 ppm) dan (10 ppm). Pengujian dilakukan dengan memipet $1 \mathrm{~mL}$ larutan sampel dari berbagai konsentrasi, kemudian masing-masing ditambahkan $1 \mathrm{~mL}$ DPPH $50 \mathrm{ppm}$ dan $2 \mathrm{~mL}$ etanol. Kemudian diinkubasi selama 30 menit pada suhu $370 \mathrm{C}$, lalu serapannya diukur pada panjang gelombang maksimum $515 \mathrm{~nm}$.

Pengukuran kadar aktivitas antioksidan ekstrak Rumput laut (Eucheuma cotonii) ${ }^{10}$

Dibuat larutan stok 2000 ppm dengan cara menimbang sampel sebanyak $50 \mathrm{mg}$, lalu 
dilarutkan dalam etanol sambil diaduk dan dihomogenkan dan dicukupkan volumenya hingga $25 \mathrm{~mL}$. Kemudian dipipet sebanyak 2,5 larutan stok 1000 ppm dicukupkan $5 \mathrm{~mL}$ dengan etanol (500 ppm). Setelah itu, dilakukan pengenceran. Masing-masing larutan dipipet sebanyak 1500, 2000, 2500, 3000 dan $3500 \mu \mathrm{L}$, kemudian masing-masing dicukupkan volumenya dengan etanol hingga 5 $\mathrm{mL}$, sehingga diperoleh konsentrasi masingmasing 600 ppm, 800 ppm, 1000 ppm, 1200 ppm dan 1400 ppm. Pengujian dilakukan dengan memipet $1 \mathrm{~mL}$ larutan sampel dari berbagai konsentrasi masing-masing. Larutan sampel ditambahkan $1 \mathrm{~mL}$ DPPH 50 ppm dan $2 \mathrm{~mL}$ etanol. Kemudian didiamkan selama 30 menit pada suhu $370 \mathrm{C}$, lalu serapannya diukur pada panjang gelombang maksimum $515 \mathrm{~nm}$.

\section{HASIL DAN PEMBAHASAN}

Antioksidan adalah senyawa yang mampu menunda, memperlambat dan mencegah proses oksidasi lipid. Dalam arti khusus antioksidan adalah zat yang dapat menunda atau mencegah terjadinya reaksi radikal bebas dalam oksidasi lipid. ${ }^{3}$
Radikal bebas merupakan molekul yang tidak stabil dan sangat reaktif karena mengandung satu atau lebih elektron tidak berpasangan pada orbit terluarnya. Untuk mencapai kestabilan, radikal bebas akan bereaksi dengan molekul disekitarnya untuk memperoleh pasangan electron. ${ }^{4}$

Metode ektraksi yang digunakan pada sampel Rumput laut (Eucheuma cotonii) adalah dengan metode maserasi karena metode tidak menggunakan pemanasan sehingga tidak terjadi penurunan atau kerusakan pada senyawa. ${ }^{5}$ Maserasi dilakukan sebanyak 3 kali dengan perbandingan pelarut 1:10, tujuannya agar proses penarikan komponen senyawa kimia yang terdapat dalam sampel Rumput laut (Eucheuma cotonii) lebih sempurna dan menghasilkan lebih banyak ekstrak etil asetat yang kemudian diuapkan dan dihasilkan ekstrak kental. Alasan digunakan pelarut etil asetat pada peneltian adalah hal ini dikarenakan pelarut etil asetat merupakan pelarut yang bersifat polar sehingga dapat menarik senyawa yang bersifat polar dan non polar. Persen rendamen ekstrak dapat dilihat pada dibawah ini, sebagai berikut:

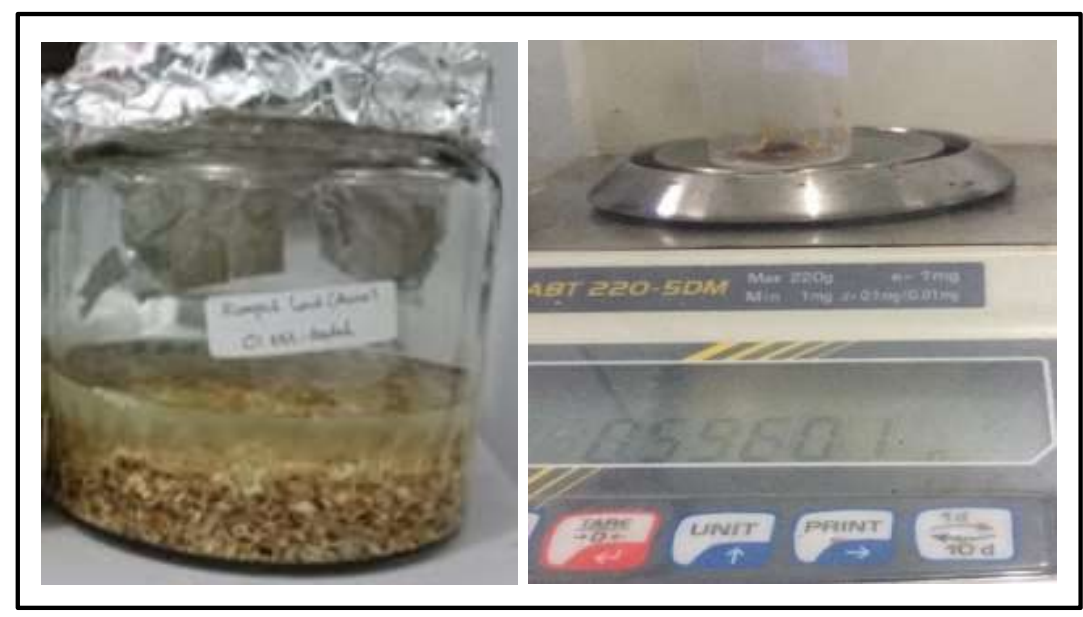

Gambar 2. Ekstrak Rumput laut (Eucheuma cotonii) 
Tabel 1. Persen rendamen ekstrak etil asetat Rumput laut (Eucheuma cotonii)

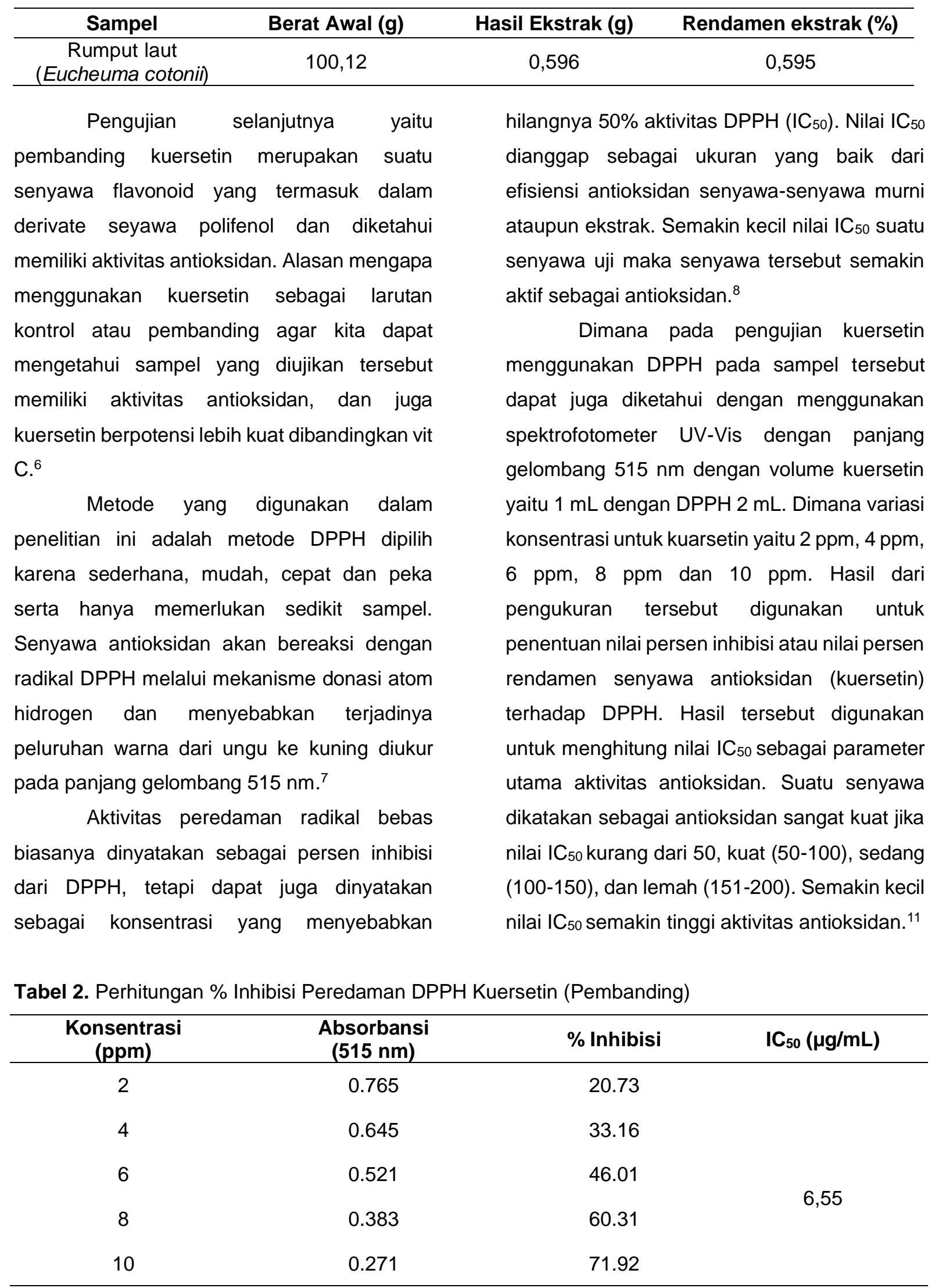


Dari hasil kurva kuersetin diatas, membuktikan bahwa nilai korelasinya mendekati 1 atau tidak kurang dari $r=0,995$ maka lineritas dari zat baku pembanding memenuhi standar untuk pengukuran zat uji dan disimpulkan bahwa semakin tinggi konsentrasi maka semakin tinggi pula nilai penghambatan yang dihasilkan. Sehingga diperoleh data tersebut dapat dilihat digambar 3 , bahwa persamaan regresi yaitu $y=6.4765 x$ + 7.567 dengan nilai konfisien kolerasi 0.9996 . Adapun nilai $\mathrm{IC}_{50}$ dari kuersetin yaitu 6,55 $\mu \mathrm{g} / \mathrm{mL}$ dan antioksidan kategori sangat kuat.

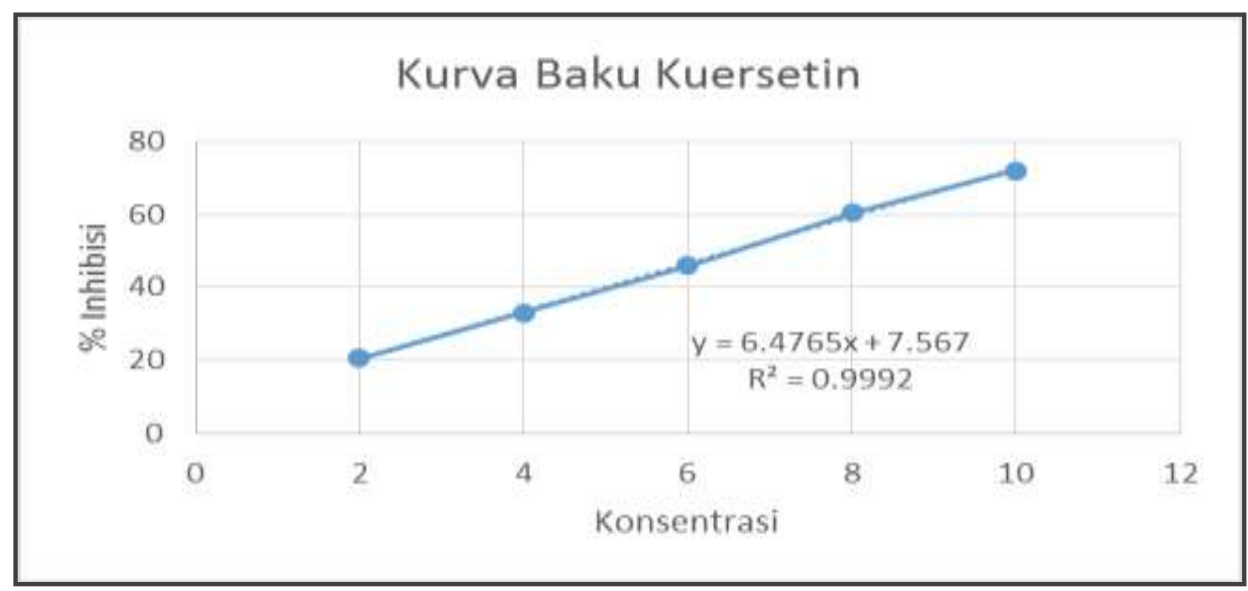

Gambar 3. Kurva kuarsetin pada panjang gelombang $515 \mathrm{~nm}$ (Abs)

Tabel 3. Perhitungan \% Inhibisi Peredaman DPPH Ekstrak Etil Asetat Rumput laut (Eucheuma cotonii)

\begin{tabular}{cccc}
\hline Konsentrasi (ppm) & Absorbansi $(\mathbf{5 1 5} \mathbf{~ n m )}$ & \% Inhibisi & $\mathbf{I C}_{\mathbf{5 0}}(\boldsymbol{\mu \mathbf { g }} \mathbf{\mathbf { m L }})$ \\
\hline 600 & 0.742 & 23.11 & \\
800 & 0.725 & 24.87 & \\
1000 & 0.707 & 26.74 & 3201.15 \\
1200 & 0.681 & 29.43 & \\
1400 & 0.664 & 31.19 & \\
\hline
\end{tabular}

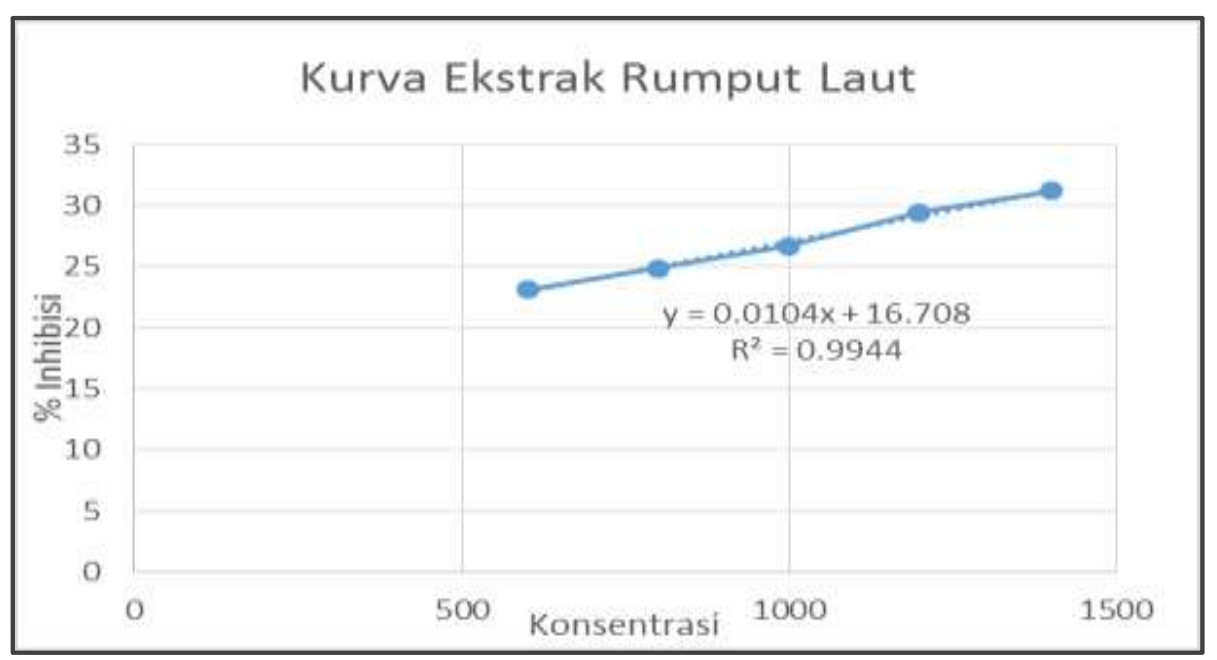

Gambar 4. Kurva ekstrak etil asetat Rumput laut (Eucheuma cotonii) pada panjang gelombang 515 $\mathrm{nm}(\mathrm{Abs})$ 
Berdasarkan gambar 4 diatas membuktikan nilai korelasi $(r)=0,995$ yang memenuhi syarat linerialitas dengan bentuk ekstrak rumput laut memiliki potensi antioksidan dengan IC50 3201.15. antioksidan rumput laut dalam bentuk ekstrak etil asetat sangatlah rendah/lemah dikarenakan masih banyaknya penumpukan senyawa yang di kategorikan kepolarannya. Karena etil asetat sifat kepolarannya rendah maka senyawa yang berada pada ekstrak tersebut hanyalah senyawa non polar dan memiliki kinerja rendah ketimbang yang sangat polar.

\section{KESIMPULAN}

Dari hasil penelitian menunjukkan ekstrak etil asetat Rumput laut (Eucheuma cotonii) memiliki nilai $\mathrm{IC}_{50}$ sebesar 3201.15 $\mu \mathrm{g} / \mathrm{mL}$ merupakan antioksidan sangat lemah dan dapat diketahui bahwa aktivitas antioksidan pada sampel ekstrak etil asetat Rumput laut (Eucheuma cotonii) memiliki tingkat dan potensi sebagai antioksidan dengan mengunakan pembanding kuersetin.

\section{DAFTAR PUSTAKA}

1. Bawa IGAG, Bawa Putra AA dan Laila IR. Penentuan $\mathrm{Ph}$ Optimum Isolasi Karaginan Dari Rumput Laut Jenis Eucheuma Cottonii. Jurnal Kimia.2007;1(1): 15-20.

2. Thevanayagam $\mathrm{H}$, Mohamed SM, Chu WL. Assessment of UVB-Photophrotective Activities of Carrageenan in Keratinocytes. Springer Science Business Media Dordrecht.2013: 1-7.

3. Ahmad AR, Mun'im A, Elya B. Study of antioxidant activity with reduction of free radical DPPH and xanthine oxidase inhibitor of the extract Ruellia tuberosa
Linn Leaf. International Research Journal of Pharmacy.2012;3(11):66-70.

4. Huliselan YM, Runtuwene MRJ, Wewengkang DS. Aktivitas Antioksidan Ekstrak Etanol, Etil Asetat, Dan n-Heksan Dari Daun Sesewanua (Clerodendron squamatum Vahl.). Pharmacon.2015;4(3):155-163.

5. Day RA and Underwood AL. Analisis Kimia Kuantitatif. Diterjemahkan oleh Lis Sopyan. Jakarta: Penerbit Erlangga, 2002.

6. Salamah N, dan Erlinda W. Aktivitas Antioksidan Ekstrak Metanol Daun Kelengkeng (Euphoria longan (L) Steud.) Dengan Metode Penangkapan Radikal 2,2'-difenil-1-pikrilhidrazil. Pharmaçiana. 2015;5(1):25-3.

7. Molyneux P. The Use Of The Stable Free Radical Diphenylpicrylhydrazyl (DPPH) For Estimating Antioxidant Activity. J. Sci.Techno.2004;26(2):211-219.

8. Husnah $\mathrm{M}$, Barroroh $\mathrm{H}$, Hayati EK. Identifikasi dan uji aktivitas golongan senyawa antioksidan ekstrak kasar buah pepino (Solanum muricatum Aiton) berdasarkan variasi pelarut (Skripsi) Malang : Universitas Islam Negeri Maulana Malik Ibrahim, 2009.

9. Rastuti $U$ dan Purwanti. Uji Aktivitas Antioksidan Ekstrak Daun Kalba Dengan Metode DPPH dan Identifikasi Senyawa Metabolit Molekul.2012;7(1):33-42.

10. Hanum F, Tarigan MA, Kaban IMD. Ekstraksi Pektin dari Kulit Buah Pisang Kepok (Musa paradisiaca). Jurnal Teknik Kimia USU. 2012;1(1): 49-53

11. Badarinath AV, RAo KM, Chetty CMS, Ramkanth V, Rajan TVS, Gnanaprakash K. A review on in-vitro antioxidant methods: comparisons, correlations and considerations. Int. J. PharmTech Res. 2010;2(2):1276-1285. 